\section{Cover essay}

(C) Springer Science + Business Media, LLC 2009

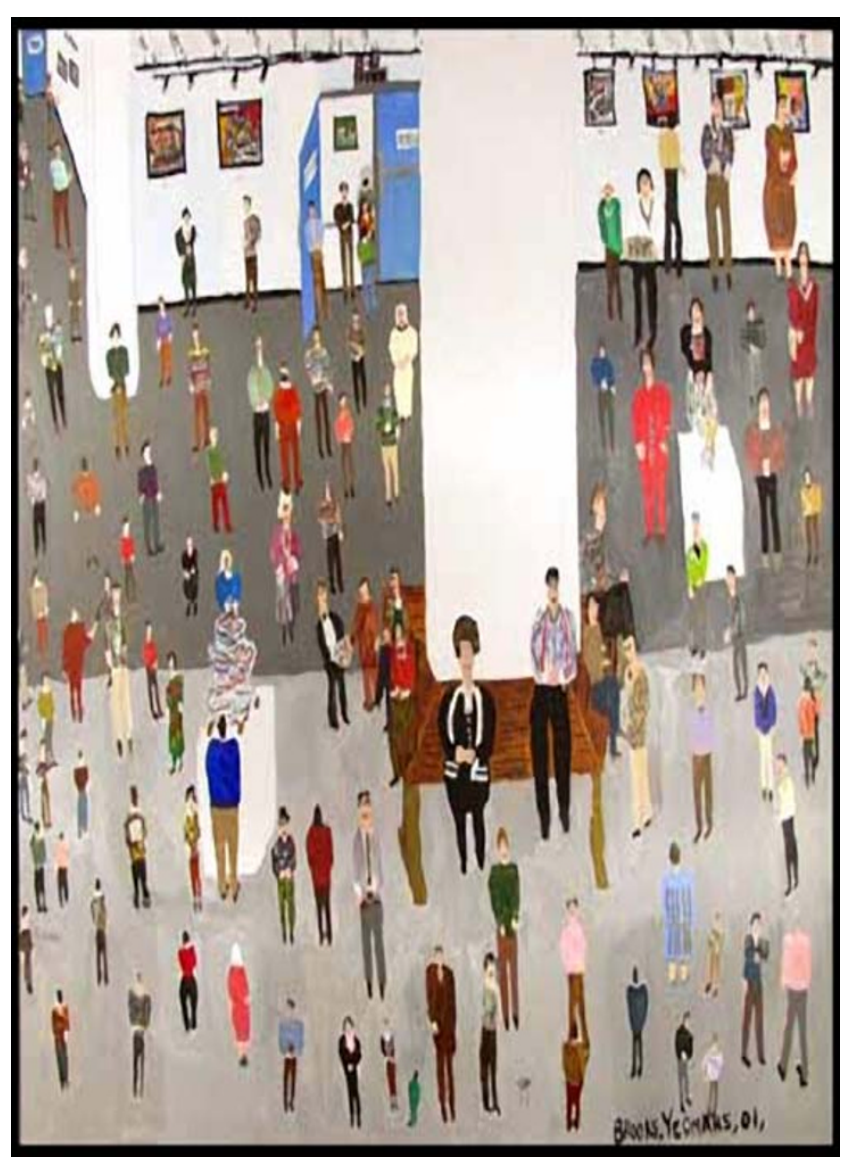

The cover painting, 'Laura McNellis' Reception' was done by artist Brooks Yeomans. Mr. Yeomans was born in 1957, in Cleveland County, North Carolina. He is currently a resident and member of 'The Enola Group', a non-profit organization for people with developmental disabilities, in Morganton, North Carolina. His talents were first recognized in 1991 with his acceptance to a group home for artistically gifted adults with developmental disabilities. With an exceptional memory for detail, Mr.Yeoman's paintings recreate scenes from everyday life with extraordinary accuracy, often painted weeks after the event. As in the cover image, his paintings take a unique 'bird's eye' perspective, rendering individuals gathered for a social reception as if they were separate objects connected more to the observing artist than to each other. Mr. Yeomans' drawings and paintings have appeared in numerous exhibits around the U.S. and internationally (http://www.enolagroup.org/artists/3/ brooks-yeomans.html). 